\title{
Stem cell membrane-coated isotretinoin for acne treatment
}

\author{
Shiyi Wang ${ }^{1}$, Rihua Jiang ${ }^{1}$, Tianqi Meng ${ }^{1}$, Fuqiang Zhang ${ }^{2}$, Jing Li ${ }^{2}$, Yongri Jin ${ }^{3}$, JeungHoon Lee ${ }^{4}$, Mingji Zhu ${ }^{1 *}$ \\ and Jinlan Jiang ${ }^{2^{*}}$
}

\begin{abstract}
Background: Topical isotretinoin is commonly used to treat acne. However, topical isotretinoin has side effects and can hardly permeate through the stratum corneum, the most important skin barrier. Therefore, this study aimed to demonstrate the efficacy of nanoparticles as stable carriers with great curative effects, low side effects, and strong transdermal ability.
\end{abstract}

Results: In a rabbit model of hyperkeratinization, STCM-ATRA-NPs showed significant therapeutic efficacy. By contrast, negative therapeutic efficacy was observed in a golden hamster model of hyper sebum production. Scanning electron microscopy and Fourier transform infrared spectral analyses showed that nanoparticles could penetrate the stratum corneum. Western blotting demonstrated that the nanoparticles could enhance the transdermal efficacy of isotretinoin by reducing the effect of keratin and tight junction proteins. Further, nanoparticles enhanced endocytosis, thereby promoting drug penetration and absorption into the skin.

Conclusion: STCM-ATRA-NPs were demonstrated to control isotretinoin release, reducing its side effects, and efficiently permeating through the skin by reducing the effect of keratin and tight junction proteins and enhancing endocytosis.

Keywords: Stem cell, Acne, Isotretinoin, Transdermal, Nanoparticles

\section{Background}

Acne is a chronic inflammatory disease and the most common dermatological disease [1], affecting about $85 \%$ teenagers worldwide, and it can persist into adulthood [2]. The disease can cause negative psychosocial consequences for the affected individual, including diminished self-esteem, social withdrawal due to embarrassment, depression, and unemployment, thus adequate therapy is needed [3]. There are four primary pathogenic factors resulting in acne, including sebum production, altered keratinization, inflammation, and bacterial

\footnotetext{
*Correspondence: zmj@jlu.edu.cn; jiangjinlan@jlu.edu.cn

${ }^{1}$ Department of Dermatology, China-Japan Union Hospital of Jilin University, Changchun, Jilin, China

${ }^{2}$ Scientific Research Center, China-Japan Union Hospital of Jilin University, Changchun, Jilin, China

Full list of author information is available at the end of the article
}

keratinization. Currently, isotretinoin is the only drug that can target each of these factors [4, 5]. Topical external retinoids are also effective acne treatments [6]. However, topical application can lead to skin irritation such as erythema $[7,8]$.

Vesicles can increase isotretinoin concentration in the skin, decreasing its side effects [9]. Liposomes and chemical synthesis of isotretinoin, tretinoin, have been reported. Yet, liposomes and chemical materials are toxic and lack biological activity [10-12]. Currently, there are limited bio-membranes as vehicles for isotretinoin delivery and effective drug carriers to penetrate the main skin barrier, the stratum corneum (SC). Stem cells are a type of primitive undifferentiated cells with self-renewal and multi-directional differentiation potential, with low immunogenicity characteristics $[13,14]$. Mesenchymal 
stem cells (MSCs) have been studied widely to elucidate their characteristics and unique properties as well as potential therapeutic applications in various diseases [15], including multiple clinical trials [16]. Many studies have used stem cell membranes (STCM) to conceal nanoparticles, showing biological characteristics such as long-term stability and drug-controlled release [17-19]. However, no study has investigated preparation of nanoparticles using STCM as a drug carrier to encapsulate small molecule drugs directly.

Transdermal delivery across the SC has garnered much attention [20]. Many approaches, including microneedling, have been attempted to improve transdermal delivery. Some studies have suggested that drug carriers (i.e., liposomes) could enhance drug penetration through fusing with SC lipids or by disturbing the intercorneocyte lipid organization [21, 22]. However, the mechanism of transdermal delivery has not been thoroughly investigated [22]. While most transdermal mechanisms focused on keratin, few studies have reported the role of tight junctions [23] and cell endocytosis [24].

In this study, the human umbilical cord mesenchymal stem cell (hMSC) membrane, as a natural liposome for drug delivery, was used to compose nanoparticles consisting of isotretinoin wrapped in the stem cell membrane (STCM-ATRA-NPs) to treat acne. Transmission electron microscopy (TEM), ultraviolet spectrophotometry, and dynamic light scattering (DLS) analyses were used to characterize STCM-ATRA-NPs. Designation of different preparation methods and ratio of stem cell membrane to isotretinoin were performed to find the appropriate encapsulation efficiency. Zeta potential was measured to investigate its stability. STCM-ATRA-NPs were shown to be small vesicles with a high encapsulation efficiency, showing stable and sustained drug release ability, less skin irritation, better treatment efficiency, and great transdermal ability. Further, we explored the transdermal mechanism by scanning electron microscopy (SEM) and Fourier transform infrared (FTIR) spectrometry to evaluate SC penetration. Finally, western blotting of endocytosis-related proteins, tight junction proteins, and keratin was conducted to investigate the mechanism of the transdermal and drug absorption pathways.

\section{Materials and methods}

\section{Cell lines and antibodies}

Human umbilical cord mesenchymal stem cell lines (hMSCs) were provided by the Scientific Research Centre of China-Japan Union Hospital, Jilin University (Changchun, China). Isotretinoin was purchased from APExBIO Technology LLC (Houston, TX, USA). Immunohistochemical antibodies against IL- 8 and TNF- $\alpha$ were purchased from Bioscience Tec LLC (Tianjin, China).
Antibodies against clathrin heavy chain were purchased from Abcam Tec (Shanghai, China). Antibodies against keratin-10, claudin-1, ZO-1, and caveolin-1 were from Affinity Biosciences (Cincinnati, OH, USA). Antibodies against GAPDH and Horseradish peroxidase (HRP)-conjugated secondary antibodies against rabbit were provided by Santa Cruz Biotechnology (Danvers, MA, USA). Enhanced chemiluminescence reagent was obtained from Pierce Biotechnology (Rockford, IL, USA).

\section{Preparation of STCM-ATRA-NPs}

HMSC membrane was prepared following published protocols [17]. Stem cells were lysed using hypotonic solution, followed by freeze-thaw disruption and differential centrifugation to get the purified stem cell membrane. To find the best way of combine the stem cell membrane with Isotretinoin (ATRA), we tried different methods, and adjusted the ratio between STCM and ATRA. ATRA was first dissolved in alcohol solution into $20 \mathrm{mg} /$ $\mathrm{mL}$, then added PBS solution into $4 \mathrm{mg} / \mathrm{mL}, 3 \mathrm{mg} / \mathrm{mL}$, $2 \mathrm{mg} / \mathrm{mL}, 1 \mathrm{mg} / \mathrm{mL}$, or $0.5 \mathrm{mg} / \mathrm{mL}$. About $4 \times 10^{6}$ stem cell derived stem cell membranes in $\mathrm{PBS}(1 \mathrm{~mL})$ were used, subsequently, added $1 \mathrm{~mL}$ isotretinoin-alcohol/ PBS solution, the mixture was placed on a constant temperature oscillator at $37^{\circ} \mathrm{C}$ for $24 \mathrm{~h}$ and $48 \mathrm{~h}$, avoiding light. Alternatively, using the Ultrasonic method, after thawing, $4 \times 10^{6}$ stem cell derived stem cell membranes in $\operatorname{PBS}(1 \mathrm{~mL})$ was placed in an ultrasound cleaner for $5 \mathrm{~min}$, the isotretinoin-alcohol/PBS solution was mixed with the stem cell membrane solution and placed in the ultrasound cleaner for $10 \mathrm{~min}$. The stem cell-coated isotretinoin was separated from uncoated isotretinoin by centrifugation at $15,000 \times g$ for $30 \mathrm{~min}$ at $4{ }^{\circ} \mathrm{C}$, keeping the supernatant for UV mesurenment.

\section{Characterization of STCM-ATRA-NPs \\ Transmission electron microscopy}

The morphology of the nanoparticles was observed by transmission electron microscopy (TEM; JEM-1230, JEOL, Tokyo, Japan). The samples were dispersed directly into bi-distilled water. A drop of the STCM-ATRA-NPs suspension was transferred to a 300-mesh carbon-coated copper grid. After staining with $2 \%(\mathrm{w} / \mathrm{v}$ ) phosphotungstic acid solution and drying at room temperature, the sample was observed by TEM at $70 \mathrm{kV}$.

\section{Determination of encapsulation efficiency of stem cell membrane-loaded isotretinoin}

To calculate encapsulation efficiency, after extruded from a $200 \mathrm{~nm}$ filter membrane, the amount of uncoated isotretinoin was measured by UV absorbance spectrophotometrically at $\lambda=355 \mathrm{~nm}$. The encapsulation efficiency was relative to the original drug added, applying 
the following equation: Encapsulation efficiency=total drug amount - unloaded drug amount/total drug.

\section{STCM-ATRA-NPs size analysis}

The freshly prepared STCM-ATRA-NPs dispersion was diluted with double diluted water, and the nanoparticles were extruded from a $400 \mathrm{~nm}$ filter membrane. Following, a Dynamic Light Scattering particle size distribution analyzer (DLS, Brookhaven BI9000AT, New York, USA) was used to characterize the vesicle size and size distribution. The vesicle size range was set between 0.1 and $20 \mathrm{~mm}$.

\section{Zeta potential of STCM-ATRA-NPs}

Zeta potential, an indicator of stability of the STCMATRA-NPs dispersion, was determined using Malvern instruments (Osaka, Japan).

\section{Ultra-violet spectrophotometry of STCM-ATRA-NPs}

An equal ATRA concentration of STCM-ATRA-NPs and STCM was sent for Ultra-violet spectrophotometry measurement at $\lambda=355 \mathrm{~nm}$.

\section{In vitro release study}

Protected from light, isotretinoin release from the stem cell membrane was performed using the Franz diffusion cell (RYJ-6B, HuangHai, Shanghai, China). These cells consisted of donor and receptor chambers separated by dialysis tubing with a molecular weight cut-off of 12,00014,000 (Spectrum Medical Inc., Los Angeles, CA, USA). The receptor cell was filled with $50 \%$ alcohol $/ 50 \%$ PBS, and $1.0 \mathrm{~mL} / 0.1 \mathrm{mg} / \mathrm{mL}$ STCM-ATRA-NPs was added to the donor cell. Samples were removed from the side arm at $0.5,24,48,72,96,120,144$, and $168 \mathrm{~h}$, and an equal volume of blank solution was added to the receptor cell. Isotretinoin concentration in samples was measured by ultra-violet spectrophotometry at $\lambda=355 \mathrm{~nm}$. Measurements were carried out in triplicate.

\section{Skin permeation test}

Isotretinoin release was measured as described above. Briefly, a 1-month-old Yorkshire pig was sacrificed for its skin, and the subcutaneous fat was removed carefully to keep the stratum corneum intact. All animal experiments were performed in accordance with the guidelines for the Care and Use of Experimental Animals of Jilin University and were approved by the Animal Experiment Ethics Committee of Jilin University. Skin was kept at $-80{ }^{\circ} \mathrm{C}$ before use. Further, skin was soaked in PBS for $1 \mathrm{~h}$ at $37^{\circ} \mathrm{C}$, and the skin was cut into small pieces (about $30 \times 30 \mathrm{~mm}$ square samples) and placed between the receptor and donor cell. Additionally, $0.25 \mathrm{mg} / \mathrm{mL}$
ATRA ( $1 \mathrm{~mL})$ and an equal weight of STCM-ATRA-NPs containing $0.25 \mathrm{mg} / \mathrm{mL}$ ATRA $(1 \mathrm{~mL})$ were added to the donor cell. An equal volume of stem cell membrane was added as the control group. The receptor cell was filled with 50\% Isopropanol and 50\% PBS without isotretinoin. Samples were taken from the receptor cell at 0.5, 1, 2, 4,6 , and $8 \mathrm{~h}$ at a volume of $0.5 \mathrm{~mL}$, filtered, and quantified by HPLC (Acchrom S6000, Huapu Tec Inc., Beijing, China). An equal volume of receiving chamber solution without isotretinoin was added to the receptor cells. All studies were run at $37^{\circ} \mathrm{C}, 100 \mathrm{rpm}$, avoiding light. Each experiment was repeated in triplicate.

\section{Skin retention test}

The amount of drug retained in the skin samples was measured in permeation studies. After a skin penetration test, the skin was removed from the receptor cell, washed with PBS three times, and cleaned to remove any adhering formulation. Following, the skin was cut into small pieces, homogenized with $20 \mathrm{~mL}$ of chloroform: methanol at a volume ratio of 1:2, and vortexed for $10 \mathrm{~min}$. After filtration using a $400 \mathrm{~nm}$ filter membrane, the drug content was measured by HPLC (Acchrom S6000).

\section{Observation of drug distribution and retention by fluorescence microscopy}

Briefly, 1-month Yorkshire pig skin was cut into small pieces and set between the receiving and donor chamber of the Franz diffusion cell. The receptor cell was filled with 50\% Isopropanol and 50\% PBS without Isotretinoin. Following, PBS, $0.25 \mathrm{mg} / \mathrm{mL}$ ATRA, STCM, and an equal volume of STCM-ATRA-NPs containing $0.25 \mathrm{mg} / \mathrm{mL}$ ATRA $(1 \mathrm{~mL})$ were added to the donor chamber. Skin was treated for $8 \mathrm{~h}$ at $37^{\circ} \mathrm{C}, 100 \mathrm{rpm}$, avoiding light. Skin tissue was fixed with $4 \%$ paraformaldehyde overnight and embedded in paraffin. Fluorescence microscopy was conducted to observe the fluorescence distribution, and ImageJ software was used to quantify fluorescence.

\section{Skin irritation test}

Briefly, 12 New Zealand white rabbits were randomly assigned to four experimental groups: normal control, ATRA, STCM, and STCM-ATRA-NPs. PBS, $0.25 \mathrm{mg} /$ $\mathrm{mL}$ ATRA cream, an equal volume of STCM, and an equal weight of ATRA-STCM-NPs containing $0.25 \mathrm{mg} /$ $\mathrm{mL}$ ATRA were applied once to each group at a dose of $0.5 \mathrm{~g}$. After $6 \mathrm{~h}$, the test area was cleaned to observe visible changes. The scores were recorded (0-4) according to evaluation standards [25], with 0 indicating no erythema, $1=$ slight erythema, $2=$ moderate erythema, $3=$ moderate-to-severe erythema, and $4=$ severe erythema. 
Treatment effect in follicular hyperkeratosis model

Male New Zealand white rabbits $(2-2.5 \mathrm{~kg}$; Changchun Biological Products Co. LTD) were housed 1 per cage under a light/dark cycle of $12 \mathrm{~h}$ with free access to water and food continuously for 5 weeks. To establish the follicular hyperkeratosis model, 15 rabbits were randomly assigned into five groups: normal control (blank), hyperkeratosis + PBS (vehicle), ATRA, STCM, and STCMATRA-NPs. Further, 12 rabbits were given coal tar once a day on the ear tube (about $2 \times 2 \mathrm{~m}^{2}$ ) for 14 days to establish the Kligman acne model. Based on established acne criteria, 0 indicates no erythema; $1=$ slight erythema, comedo; $2=$ moderate erythema, comedo; $3=$ moderateto-severe erythema, comedo; and $4=$ severe erythema, comedo. Histological changes were evaluated by $H \& E$ staining and IHC staining.

\section{Treatment effect in hyper sebum production model}

Male golden hamsters (6-8 weeks, 80-120 g) were used to establish a hyper sebum production model. Hair was removed carefully to expose the two sides of the sebaceous glands, and the hamsters were randomly divided into four groups: normal control (blank), ATRA, STCM, and STCM-ATRA-NPs. Formulations were given once daily, and the animals were sacrificed on day 14. Histological changes were evaluated by H\&E staining.

\section{Scanning electron microscopy and Fourier infrared spectrum analysis}

Briefly, 1-month-old Yorkshire pig skin was processed in the Franz diffusion cell, as described above. The receptor cell was filled with 50\% Isopropanol and 50\% PBS without Isotretinoin. Further, PBS, $0.25 \mathrm{mg} / \mathrm{mL}$ ATRA, STCM, and an equal volume of STCM-ATRA-NPs containing $0.25 \mathrm{mg} / \mathrm{mL}$ ATRA $(1 \mathrm{~mL})$ were added to the donor chamber. Skin was treated for $8 \mathrm{~h}$ at $37{ }^{\circ} \mathrm{C}$, $100 \mathrm{rpm}$, avoiding light. For SEM analysis, the skin was fixed with glutaraldehyde for $24 \mathrm{~h}$, freeze-dried for $48 \mathrm{~h}$, and observed using a scanning electron microscope (Carl Zeiss Microscopy GmbH, Oberkochen, Germany) to assess changes in the Horney layer of the skin layer at $200 \times$ and $900 \times$ magnification. For Fourier infrared (FTIR) spectral analysis, the skin was removed from the freeze-drying machine after $48 \mathrm{~h}$, ground with potassium bromide using an agate mortar, and analyzed at resolution: $2 \mathrm{~cm}^{-1}$, scanning times: 100 , and scan range: 650 $4000 \mathrm{~cm}^{-1}$ to assess changes in keratin.

\section{Western blotting}

Briefly, 1-month-old Yorkshire pig skin was processed in the Franz diffusion cell, as described above. After treatment for $8 \mathrm{~h}$ at $37^{\circ} \mathrm{C}, 100 \mathrm{rpm}$, avoiding light, the skin was removed and ground in liquid nitrogen for protein extraction. Ice-cold lysis buffer was used to treat skin tissue samples, and the relative concentrations were determined by BCA protein kit. The supernatants of the cell lysates were then separated by $12 \%$ SDS-PAGE gels and transferred onto PVDF membranes, which were subsequently blocked with $5 \%$ no-fat milk. Finally, the membranes were reacted with primary antibodies for $12 \mathrm{~h}$, followed by keratin-10, claudin-1, ZO-1, caveolin-1 and clathrin heavy chain secondary antibodies.

\section{Statistical analysis}

All data are given as mean \pm standard error (SE). Statistical analyses were performed using two-sample Student's $t$ tests and ANOVAs, followed by an LSD post hoc test. $P<0.05$ was considered statistically significant.

\section{Results}

Synthesis and characterization of ATRA-STCM-NPs

STCM-coated isotretinoin using different methods and components showed different encapsulate efficiencies, and the results are shown in Table 1 . The standard curve of Isotretinoin is $y=183.22 x-5.5199, R^{2}=0.9996$ (Isotretinoin as standard dissolved in a $50 \% \mathrm{PBS} / 50 \%$ alcohol).The ultrasonic approach appeared to be much better than the oscillator method. Oscillator-generated stem cell membrane-coated ATRA were shown as irregular and huge particles in TEM (Fig. 1j) and microscope (Fig. 1k) observation. For further observation, stem cell membrane were labeled with fluorescence probe $(\mathrm{PKH}-$ 26, Sigma-Aldrich, shanghai, China), it could seen that the fluorescence of cell membrane (Fig. 11) coincided with that of ATRA (Fig. 1m). In TEM observations of the morphology of ultrasonic-generated STCMATRA-NPs, homogeneous, rounded nanoparticles were observed. As such, the ultrasonic method at the ratio

\section{Table 1 Encapsulation efficiency of STCM-ATRA-NPs}

\begin{tabular}{llll}
\hline Serial number & $\begin{array}{l}\text { Concentration } \\
\text { of isotretinoin } \\
(\mathbf{m g} / \mathbf{m L})\end{array}$ & $\begin{array}{l}\text { Encapsulation } \\
\text { method } \\
\text { and time }\end{array}$ & $\begin{array}{l}\text { Encapsulation } \\
\text { efficiency }(\%)\end{array}$ \\
\hline 1 & 4 & Ultrasonic & 80.07 \\
2 & 3 & Ultrasonic & 88.59 \\
3 & 2 & Ultrasonic & 78.98 \\
4 & 1 & Ultrasonic & 42.07 \\
5 & 4 & Oscillator (24 h) & 30.04 \\
6 & 3 & Oscillator (24 h) & 28.54 \\
7 & 2 & Oscillator (24 h) & 27.33 \\
8 & 1 & Oscillator (24 h) & 15.42 \\
9 & 4 & Oscillator (48 h) & 32.49 \\
10 & 3 & Oscillator (48 h) & 31.32 \\
11 & 2 & Oscillator (48 h) & 27.54 \\
12 & 1 & Oscillator (48 h) & 16.08 \\
\hline
\end{tabular}



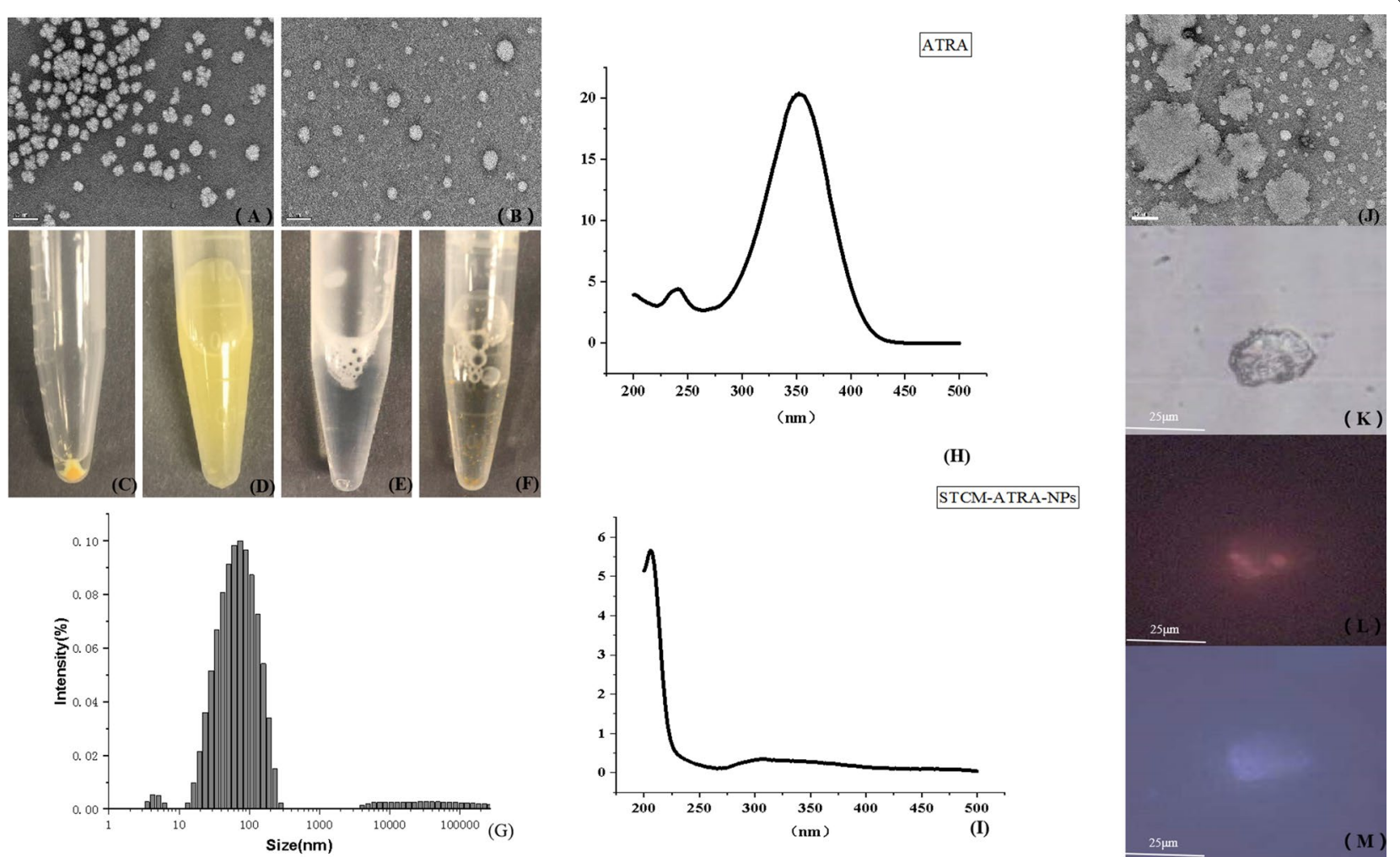

Fig. 1 Characterization of STCM-ATRA-NPS. a Morphology of stem cell membrane by TEM. b Morphology of STCM-ATRA-NPS, c freshly prepared STCM-ATRA-NPS, $\mathbf{d}$ STCM-ATRA-NPs in PBS, e stem cell membrane in PBS, and $\mathbf{f}$ isotretinoin in PBS. $\mathbf{g}$ Size of STCM-ATRA-NPs measured by DLS and $\mathbf{h}$ ATRA and $\mathbf{i}$ STCM-ATRA-NPs measured by ultra violet spectrum. $\mathbf{j}$ Morphology of oscillator-generated STCM-ATRA-NPs by TEM. $\mathbf{k}$ Morphology of oscillator-generated STCM-ATRA-NPs by microscope. I Morphology of oscillator-generated STCM-ATRA-NPs by fluorescence microscopy under blue fluorescence and $\mathbf{m}$ under ultraviolet

of $4 \times 10^{6}$ stem cells derived membranes and $3 \mathrm{mg} / \mathrm{mL}$ ATRA $(1 \mathrm{~mL})$ was selected to generate STCM-ATRANPs for subsequent analysis.

Isotretinoin appeared to be insoluble in water, with yellow particles deposited at the bottom of the tube (Fig. 1f). However, isotretinoin dissolved in ethanol, becoming a transparent yellow liquid. Stem cell membrane dissolved in water appeared as a colorless and transparent liquid. After mixing ATRA-alcohol and STCM solutions together by the ultrasonic method, followed by centrifugation at $15,000 \times g$, the yellow precipitate (STCM-ATRA-NPs) dissolved in water, forming a yellow suspension. The DLS results showed that the mean diameter of nanoparticles is $56.9 \mathrm{~nm}$ (Std deviation $=0.221$ ), which is consistent with the TEM results (Fig. 1g). To confirm the new nanoparticle, using the UV spectrum to test the unique peak of ATRA, STCMATRA-NPs did not show the unique absorption peak, which may be due to embedding of isotretinoin molecules in the lipid bilayer of the stem cell membrane. The zeta potential of STCM-ATRA-NPs is $-34.9 \mathrm{mV}$, STCM-ATRA-NPs showed great stability.

\section{Sustained release of nanoparticles in in vitro release study} Figure 2a shows the in vitro release profiles of STCMATRA-NPs, demonstrating sustained release function. The overall release of ATRA from the STCM-ATRA-NPs was very slow, which may provide a better therapeutic effect. The results showed that ATRA can be released completely from the stem cell membrane at $168 \mathrm{~h}$. Isotretinoin was shown to be very unstable and easily decomposed, while ATRA released from the stem cell membrane showed great stability.

\section{Greater transdermal ability of nanoparticles in skin permeation test}

Figure $2 \mathrm{~b}$ shows that STCM-ATRA-NPs demonstrated greater transdermal ability than free ATRA. Further, stem cell membrane-coated isotretinoin showed faster permeation across the skin than the Isotretinoin.

\section{Higher skin retention of nanoparticles}

Skin retention of ATRA in skin was detected by HPLC measurement, STCM-ATRA-NPs group is $0.45 \pm 0.13 \mu \mathrm{g}$ $(\mathrm{n}=3)$, while ATRA group is $3.03 \pm 0.17 \mu \mathrm{g}(\mathrm{n}=3)$. HPLC 
a

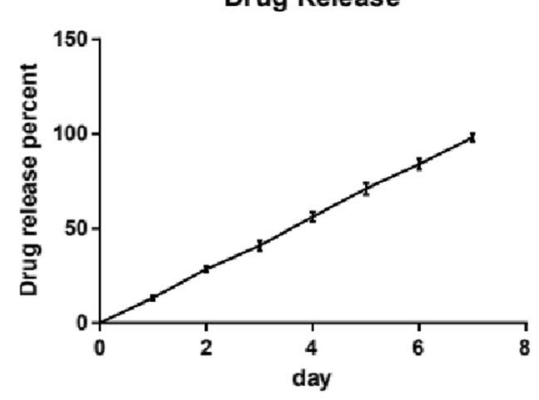

c

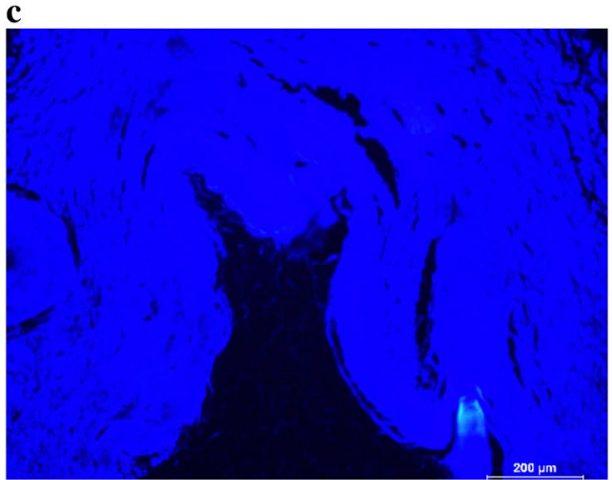

b

b Skin Penetration

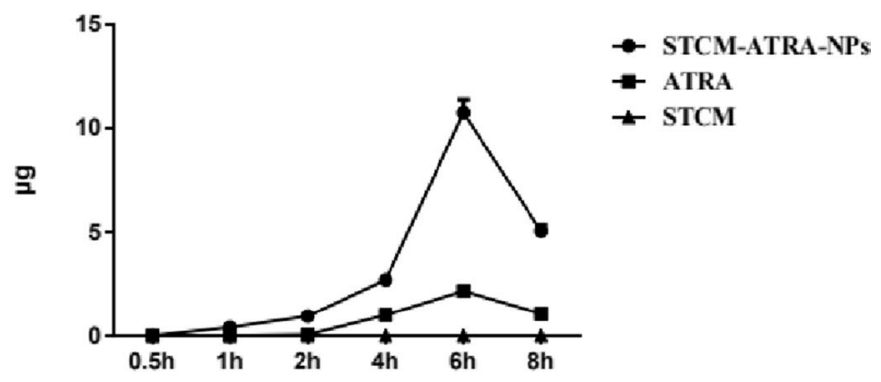

d

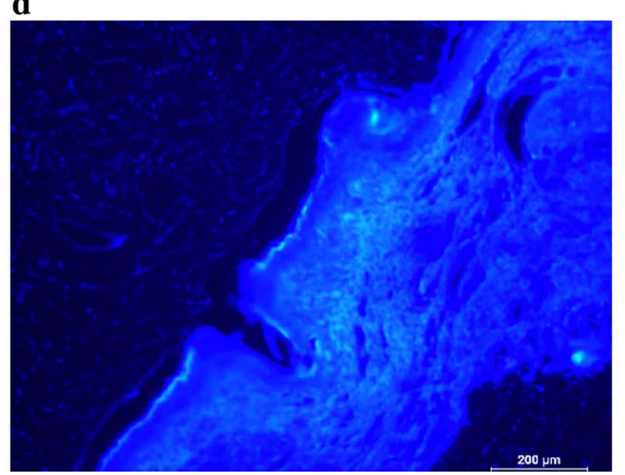

Fig. 2 Drug loading characters of STCM-ATRA-NPs. a Controlled release of ATRA from STCM-ATRA-NPs, followed daily at $37^{\circ} \mathrm{C}$ in a hydroalcoholic solution, up to 7 days. $\mathbf{b}$ Penetration of ATRA and STCM-ATRA-NPs through the pig dermis, monitored over $8 \mathrm{~h}$. Data shown are mean \pm S.D., $\mathrm{n}=3$. Franz diffusion cell of $\mathbf{c}$ ATRA and $\mathbf{d}$ STCM-ATRA-NPs for $8 \mathrm{~h}$ at $37^{\circ} \mathrm{C}$ and $100 \mathrm{rpm}$. STCM-ATRA-NPs at $8 \mathrm{~h}$ showed more uniform distribution and accumulation compared to ATRA

results showed that STCM-ATRA-NPs were retained in skin much less than ATRA. Both STCM-ATRA-NPs and ATRA can show white fluorescence of under UV excitation $(365 \mathrm{~nm})$. From observation of fluorescence microscope, fluorescence of STCM-ATRA-NPs (Fig. 2d) appeared much stronger than free ATRA (Fig. 2c), and STCM-ATRA-NPs were distributed more uniformly than free ATRA. The opposite results may because STCMATRA-NPs barely have no absorbance at $\lambda=355 \mathrm{~nm}$, it can not be measured by HPLC, it may indicated ATRA were slowly release from STCM-ATRA-NPs in skin.

\section{Reduced skin irritation by nanoparticles}

Figure 3 shows that after $6 \mathrm{~h}$, the STCM-ATRA-NPs group showed no erythema to very slight erythema, while isotretinoin caused slight to moderate erythema $(\mathrm{P}=0.016)$. Additionally, the STCM group showed no erythema.

\section{Greater treatment efficiency in hyperkeratinization model}

Figure 4 shows that STCM-ATRA-NPs had a great therapeutic effect in a hyperkeratinization model. Apparently, STCM-ATRA-NPs reduced comedo. After 14-day treatment, the STCM-ATRA-NPs group had no comedo or slight comedo. ATRA and STCM groups showed slightto-moderate comedo $(\mathrm{P}=0.116)$.

From H\&E staining results (Fig. 4), STCM-ATRANPs caused no follicular keratotic plugging, indicating reduced hyperkeratinization. However, there were no significant differences in IL- 8 and TNF- $\alpha$ expression, two major inflammatory factors in acne, between STCM-ATRA-NPs and ATRA groups (Fig. 5), indicating STCM-ATRA-NPs may not effectively impact inflammation. Further, no obvious change in hyper sebum production was observed, as measured by sebaceous glands volume and the number of leaf layers of sebaceous glands (Fig. 6).

\section{Altered morphology of the skin Horney layer}

Figure 7 shows that STCM-ATRA-NPs could penetrate the main skin barrier. The effects of the stem cell membrane and STCM-ATRA-NPs on the structure of the corneum were observed by SEM. Compared with the control group, the stem cell membrane and STCMATRA-NPs created a porous structure, destroying its original smooth surface. 

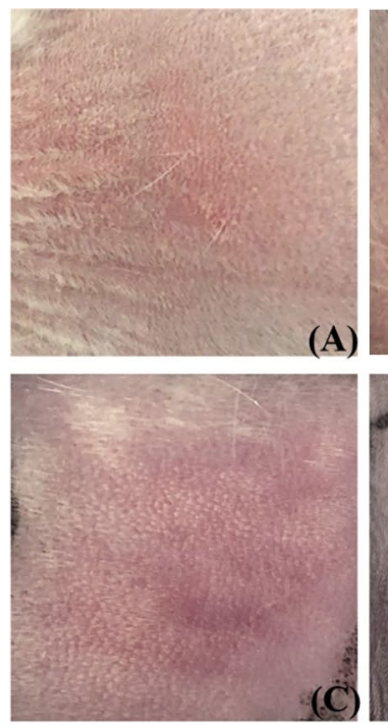

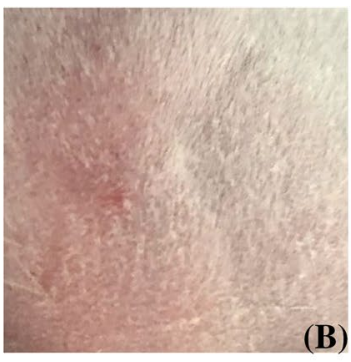

(B)

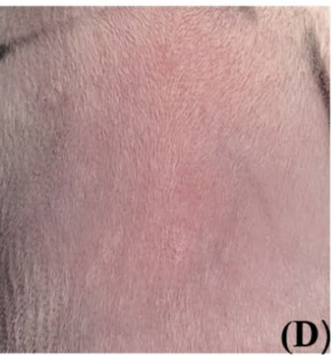

(D)

\section{Criteria of Skin Irritation}

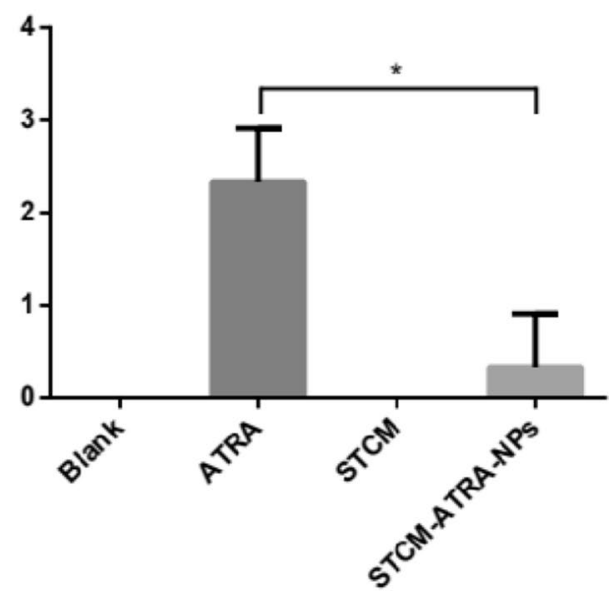

Fig. 3 Skin irritation by STCM-ATRA-NPS. Skin application of a PBS, b STCM, c ATRA, or d STCM-ATRA-NPs for 6 h. e Criteria of skin irritation. Data shown are mean \pm S.D., $n=3$
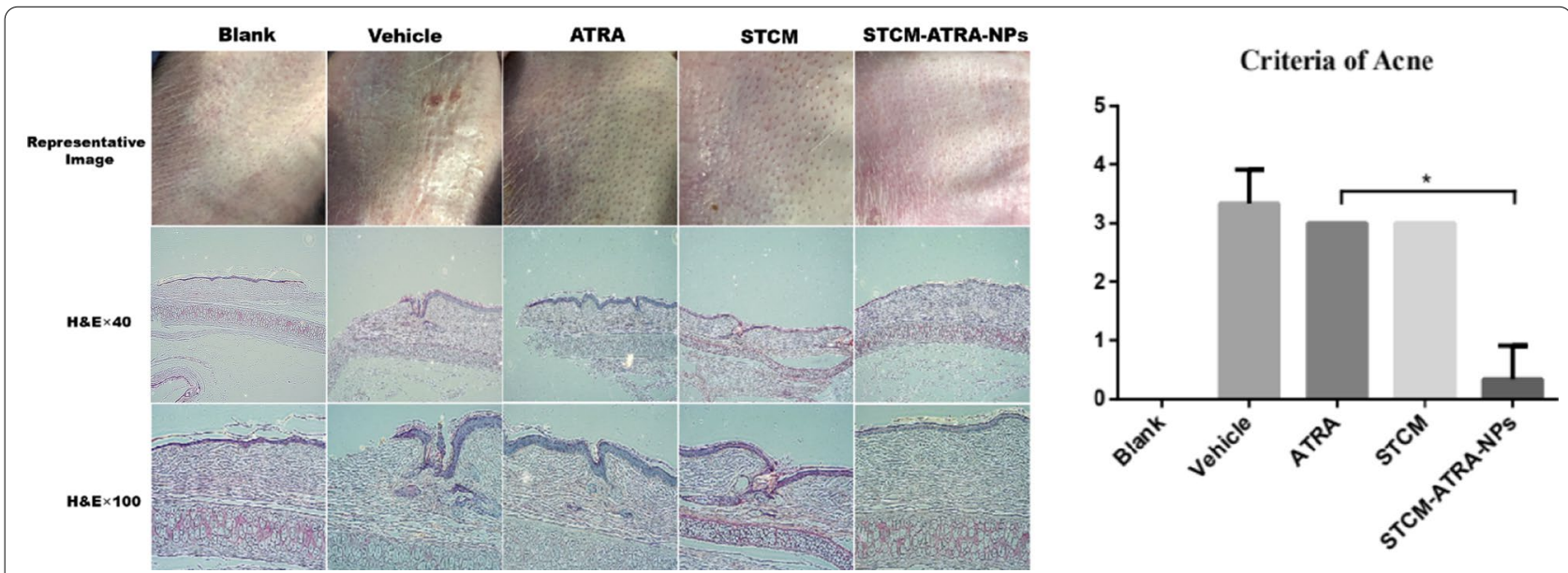

Fig. 4 Treatment efficiency on hyper keratinization model by H\&E staining. Representative image, HE staining (at $\times 40$ and $\times 200$ magnification), and acne criteria of hyper keratinization model

\section{Altered expression of endocytosis-related proteins}

Compared to the ATRA group, the STCM-ATRANPs group showed reduced expression of the keratin 10 proteins. By contrast, endocytosis-related proteins clathrin heavy chain and caveolin-1 were increased, which may indicate that STCM-ATRA-NPs permeated through the skin via an endocytosis pathway and removed the barrier of the $\mathrm{SC}$ and tight junctions [26, 27] (Fig. 8a). Our results showed that caveolin-1 was increased, suggesting that the STCM-ATRA-NPs transdermal behavior is dependent on caveolin-1 mediated endocytosis [28].

\section{Altered keratin structure in the skin}

FITR analysis indicated disruption of keratin in skin. The special absorption peak of keratin in the SC was the stretching vibration of amides I $\left(1600-1700 \mathrm{~cm}^{-1}\right)$ and amides II (1500-1600 $\mathrm{cm}^{-1}$ ) (Fig. 8b). However, the unique peak of amides I and amides II was changed slightly, indicating that the alpha helix of keratin in the skin was destroyed, and the structure of keratin in the skin had changed. 


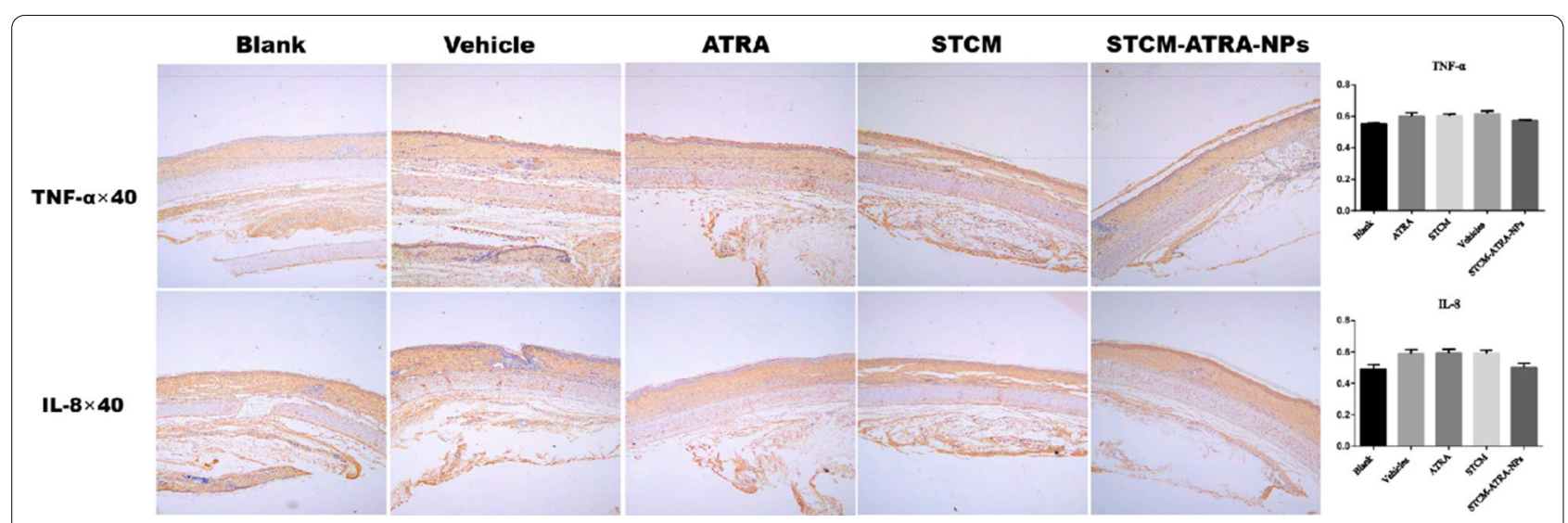

Fig. 5 Treatment efficiency on hyper keratinization model by IHC staining. Representative images and quantification of IL-8 and TNF-a IHC staining of hyper keratinization acne model. Data shown are mean \pm S.D., $n=3$

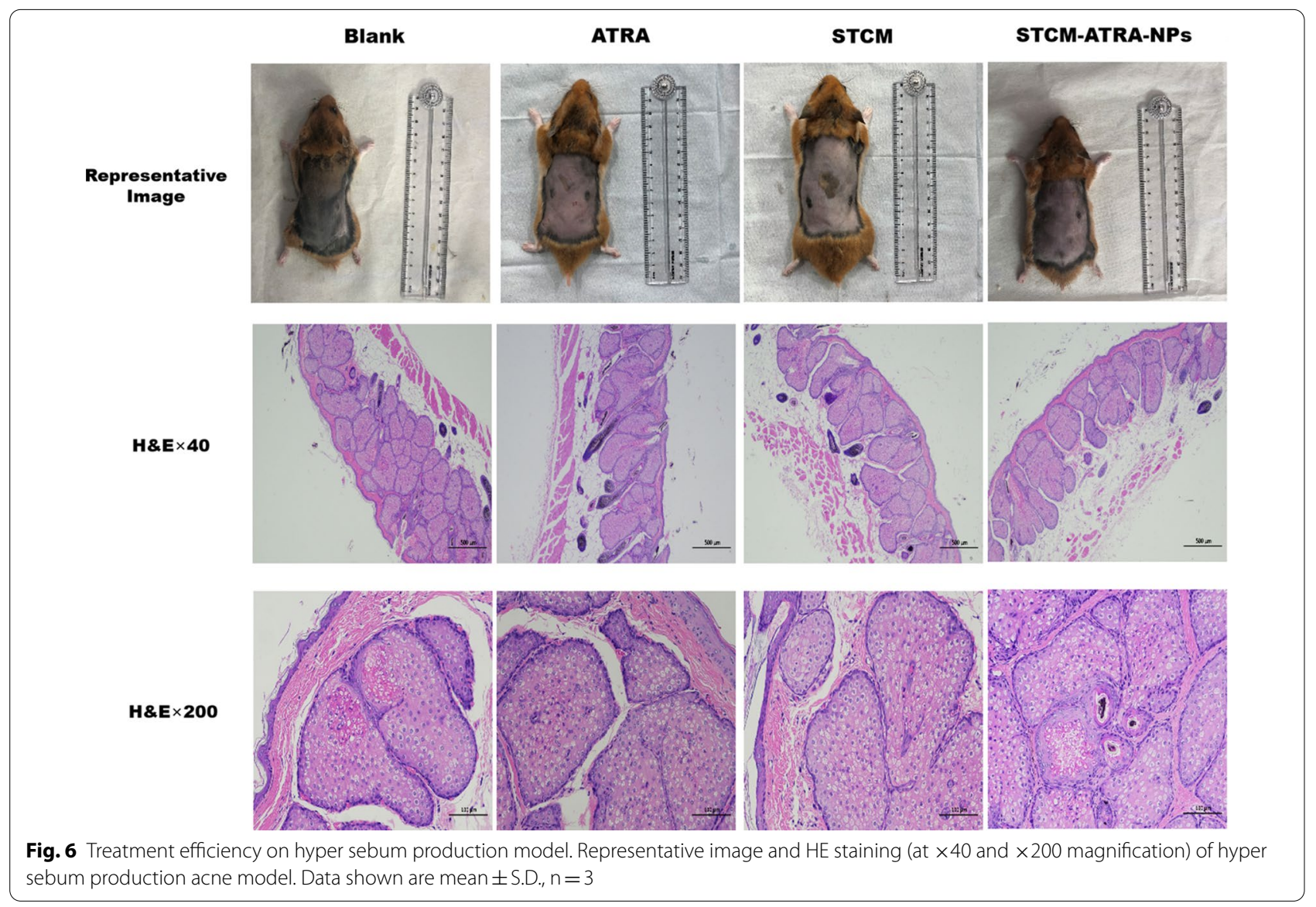

\section{Discussion}

Overall, our study established a new approach of coating isotretinoin in a stem cell membrane, discovering the function of endocytosis-related keratin and tight junction proteins in the nanoparticle's transdermal pathway. Most isotretinoin drug carriers are liposomes and generated through chemical synthesis, which are relatively toxic. This study describes the natural cell membrane as a drug delivery system. STCM-ATRA-NPs are small (less than $100 \mathrm{~nm}$ ), stable nanoparticles. Isotretinoin is easy to oxidize and photolyze [29], but it shows great stability when combined with the stem cell membrane. Compared with 

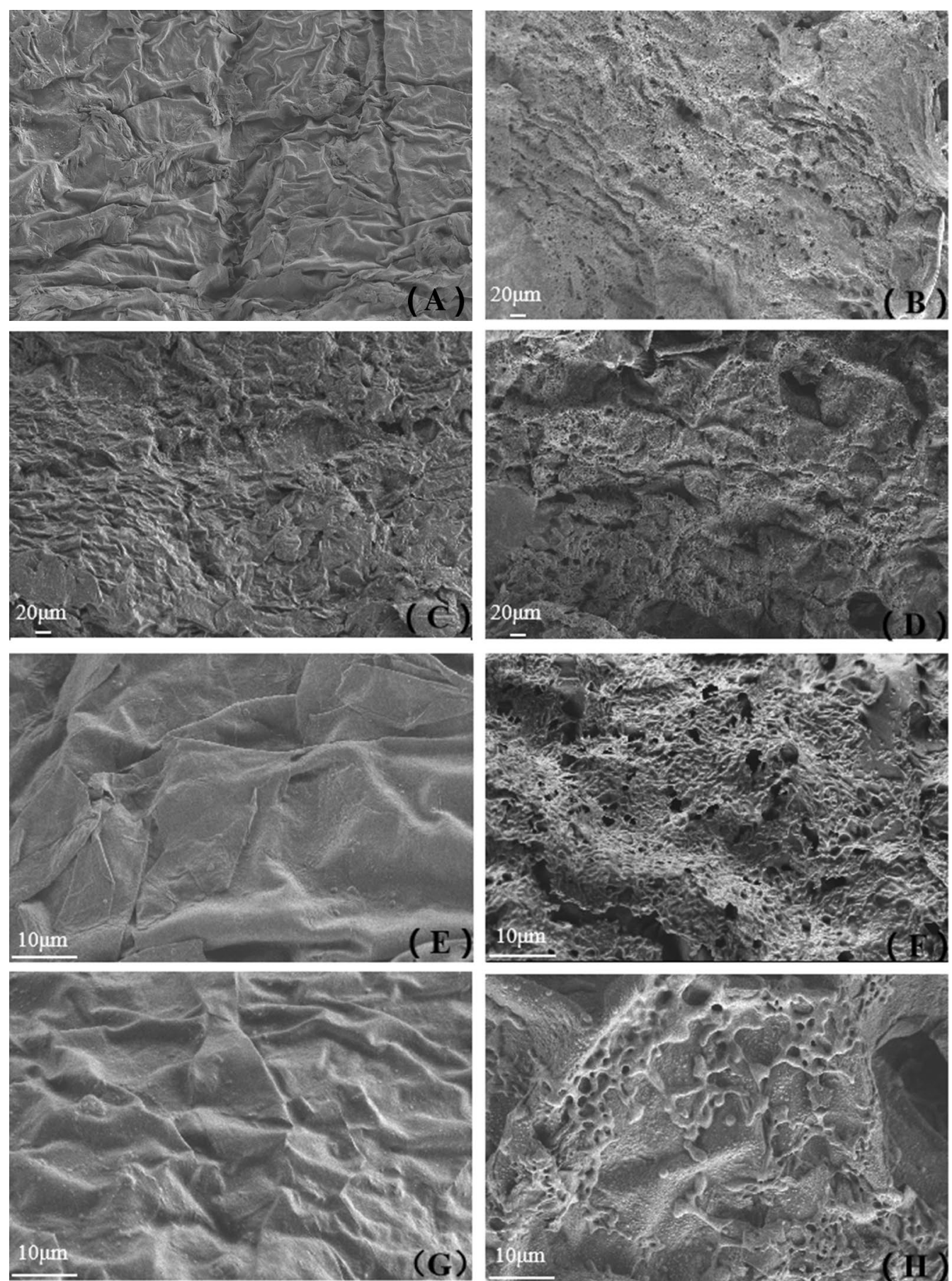

Fig. 7 Morphology of the skin Horney layer. Skin treated with a PBS, b STCM, c ATRA, or d STCM-ATRA-NPs for 6 h, at $\times 200$ magnification. Skin treated with e PBS, $\mathbf{f}$ STCM, $\mathbf{g}$ ATRA, or $\mathbf{h}$ STCM-ATRA-NPs for 8 h, at $\times 900$ magnification

the traditional isotretinoin gel, the stem cell membrane can help to preserve isotretinoin, effectively preventing isotretinoin decomposition. Further, the stem cell membrane can control release up to 7 days, which is an ideal feature of a great drug carrier. We established two acne models to evaluate the effect of STCM-ATRA-NPs on different acne pathogeneses. The hyper keratinization model showed an acceptable result, in which it worked effectively on hyperkeratinization. However, it showed no effect on hyper sebum production, which may be the 

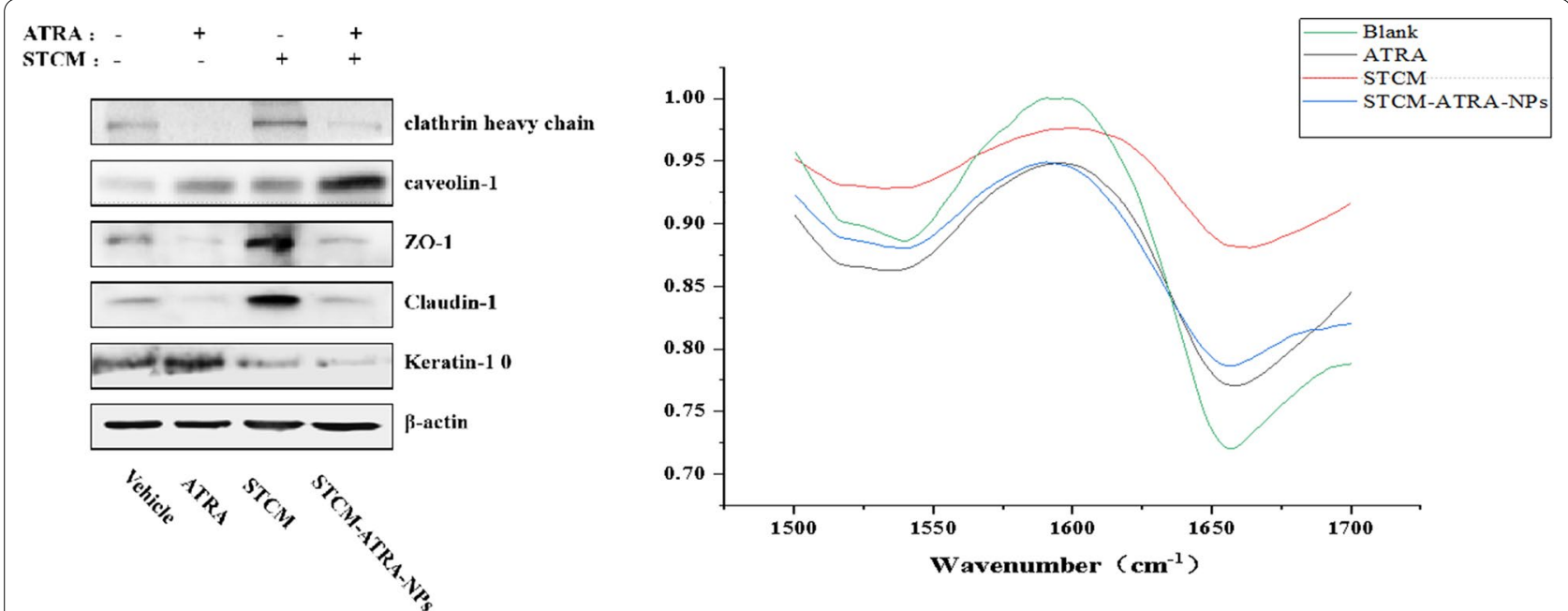

Fig. 8 Mechanism of STCM-ATRA-NP transdermal enhancement. a The levels of endocytosis-related proteins, tight junction-related proteins, and the main protein of the LC layer treated by PBS, ATRA, STCM, and STCM-ATRA-NPs, in a Franz diffusion cell for $8 \mathrm{~h}$, as measured by western blot. $\mathbf{b}$ The change in keratin as analyzed by Fourier infrared spectral analysis

result of the impact of STCM-ATRA-NPs on keratin and tight junctions. Yet, they may not permeate through sebaceous glands tissue completely, which requires further investigation.

The skin retention test and distribution observed by fluorescence microscopy demonstrated that STCMATRA-NPs can facilitate isotretinoin retention in skin. By contrast, the skin retention study showed the opposite results, suggesting that isotretinoin may not have been thoroughly released from STCM-ATRA-NPs, which may continue over several days. Further, the STCM-ATRANPs distribution results showed uniformity in density distribution, which may reduce side effects and provide better treatment.

The skin permeation study indicated that STCMATRA-NPs had great transdermal ability. Moreover, the western blot, SEM, and FTIR observations indicated the potential mechanism of STCM-ATRA-NPs improvement of transdermal activity. Some studies suggest that drug carriers transform to permeate the SC layer of the skin $[29,30]$, while others have shown that liposomes as drug carrier can impact keratin to enhance skin penetration [31, 32]. In our study, western blot, FTIR, and SEM findings all demonstrated that keratin was disrupted and decreased in the skin. Since the SC layer had some porous structures, STCM-ATRA-NPs may enter the SC layer through these pores, which is much faster than transformation. Further, tight junction proteins were decreased, while the functional proteins of endocytosis were increased. By contrast, after sealed with ATRA, keratin content increased, the endocytosis protein caveolin-1 slightly increased, but the endocytosis protein clathrin heavy chain was significantly decreased. Further, the tight junction protein was strongly increased with the stem cell membrane, which is in contrast to treatment by STCM-ATRA-NPs, and both the clathrin heavy chain and caveolin-1 protein were increased, indicating that the stem cell membrane can enter cells through two endocytic mechanisms, while STCM-ATRA-NPs can enter mainly through caveolin-1 protein-related pathways. Bioactivity of STCM-ATRA-NPs differs from the stem cell membrane, but the reason and mechanism still need further investigation. The different tendency of stem cell membrane and STCM-ATRA-NPs is related to the interact between tight junctions and the corneum layer. However, the mechanism by which the stem cell membrane interacts in this process still needs to be further explored. The tight junction and LC layer, as the two main barriers of transdermal delivery, are believed to interact with each other and alter lipid organization [33]. Based on our findings, we hypothesize that the LC layer, tight junction, and endocytosis all play an important part in the mechanism of transdermal delivery and can interact with each other (Fig. 9). However, this mechanism still needs further study.

\section{Conclusion}

In conclusion, the STCM-ATRA-NPs demonstrated control isotretinoin release, reduced side effects, and efficiently permeating through the skin, it also showed significant therapeutic efficacy. We further demonstrated that the nanoparticles could enhance the transdermal efficacy of isotretinoin by reducing the effect of keratin and tight junction proteins. Further, nanoparticles 

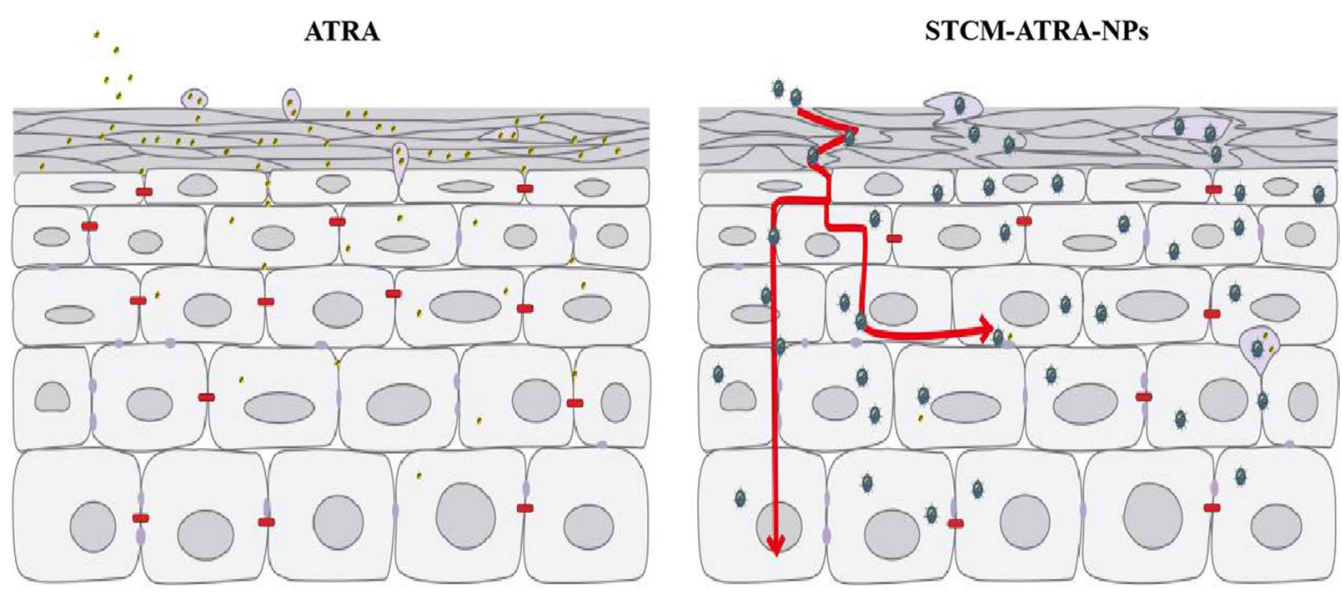

Fig. 9 Proposed mechanism of STCM-ATRA-NP transdermal ability

enhanced endocytosis, thereby promoting drug penetration and absorption into the skin.

\section{Abbreviations}

ATRA: Isotretinoin; BCA: Bicinchoninic acid; BSA: Bovine serum albumin; DLS: Dynamic light scattering; FBS: Fetal bovine serum; FTIR: Fourier transform infrared; H\&E: Hematoxylin and eosin; hMSC: Human umbilical cord mesenchymal stem cell; HPLC: High-performance liquid chromatography; HRP: Horseradish peroxidase; IHC: Immunohistochemistry: PBS: Phosphate buffered saline; PVDF: Polyvinylidene fluoride; SC: Stratum corneum; STCM: Stem cell membrane; STCM-ATRA-NPs: Stem cell membrane-coated isotretinoin nanoparticles; SEM: Scanning electron; TEM: Transmission electron microscope.

\section{Acknowledgements}

This study was supported by the Department of Science and Technology of Jilin Province, (20170414056GH) and Youth Program of National Natural Science Foundation of China (51703077)

\section{Authors' contributions}

SW designed the study and performed the vitro experiments; SW, RJ, and TM performed the animal experiments, SW carried out the biological experiments, $F Z, J L, Y J$, and JHL helped with the biological study; SW, MZ, and JJ supervised the whole work and wrote the manuscript. All authors read and approved the final manuscript.

\section{Funding}

This work was supported by the Department of Science and Technology of Jilin Province, (20170414056GH) and Youth Program of National Natural Science Foundation of China (51703077) in the design of the study and analysis of data.

\section{Availability of data and materials}

Data sharing not applicable to this article as no datasets were generated or analyzed during the current study.

\section{Ethics approval and consent to participate}

This study was approval by the Ethic Committee at Jilin university. The use of the clinical specimens and animal for research purposes was in accordance with the Declaration of Helsinki, and the research did not contain any individual person's data in any form.

\section{Competing interests}

The authors declare that they have no competing interests.

\section{Author details}

${ }^{1}$ Department of Dermatology, China-Japan Union Hospital of Jilin University, Changchun, Jilin, China. ${ }^{2}$ Scientific Research Center, China-Japan Union Hospital of Jilin University, Changchun, Jilin, China. ${ }^{3}$ College of Chemistry, Jilin University, Changchun, Jilin, China. ${ }^{4}$ Department of Dermatology, School of Medicine, Chungnam National University, Daejeon, Republic of Korea.

Received: 26 March 2020 Accepted: 20 July 2020

Published online: 28 July 2020

\section{References}

1. Moradi Tuchayi S, Makrantonaki E, Ganceviciene R, Dessinioti C, Feldman SR, Zouboulis CC. Acne vulgaris. Nat Rev Dis Primers. 2015;1:15029.

2. Zaenglein AL. Acne vulgaris. N Engl J Med. 2018;379:1343-52.

3. Brown SK, Shalita AR. Acne vulgaris. Lancet. 1998:351:1871-6.

4. Owen CE. Treating acne with high-dose isotretinoin. JAMA. 2014:311:2121-2.

5. Williams HC, Dellavalle RP, Garner S. Acne vulgaris. Lancet. 2012:379:361-72

6. Haider A, Shaw JC. Treatment of acne vulgaris. JAMA. 2004;292:726-35.

7. Brisaert M, Gabriels M, Matthijs V, Plaizier-Vercammen J. Liposomes with tretinoin: a physical and chemical evaluation. J Pharm Biomed Anal. 2001:26:909-17.

8. Elbaum DJ. Comparison of the stability of topical isotretinoin and topical tretinoin and their efficacy in acne. J Am Acad Dermatol. 1988;19:486-91.

9. Imbert D, Kasting GB, Randall WR. Influence of liposomal encapsulation on penetration of retinoic acid through human skin in vitro. J Soc Cosmet Chem. 1994:45:119-34

10. Rahman SA, Abdelmalak NS, Badawi A, Elbayoumy T, Sabry N, El Ramly A. Formulation of tretinoin-loaded topical proniosomes for treatment of acne: in vitro characterization, skin irritation test and comparative clinical study. Drug Deliv. 2015;22:731-9.

11. Castleberry SA, Quadir MA, Sharkh MA, Shopsowitz KE, Hammond PT. Polymer conjugated retinoids for controlled transdermal delivery. J Control Release. 2017;262:1-9.

12. Simonart T. Newer approaches to the treatment of acne vulgaris. Am J Clin Dermatol. 2012:13:357-64.

13. Shu X, Pei D. Pluripotency without proliferation. Cell. 2016;164:595-7.

14. Weissman IL. Stem cells: units of development, units of regeneration, and units in evaluation. Cell. 2000;100:157-68.

15. Bianco P, Cao X, Frenette PS, Mao JJ, Robey PG, Simmons PJ, et al. The meaning, the sense and the significance: translating the science of mesenchymal stem cells into medicine. Nat Med. 2013;19:35-42. 
16. Squillaro T, Peluso G, Galderisi U. Clinical trials with mesenchymal stem cells: an update. Cell Transplant. 2006;25:829-48.

17. Gao C, Lin Z, Jurado-Sánchez B, Lin X, Wu Z, He Q. Stem cell membranecoated nanogels for highly efficient in vivo tumor targeted drug delivery. Small. 2016;12:4056-62.

18. Yang N, Ding Y, Zhang Y, Wang B, Zhao X, Cheng K, et al. Surface functionalization of polymeric nanoparticles with umbilical cord-derived mesenchymal stem cell membrane for tumor-targeted therapy. ACS Appl Mater Interfaces. 2018;10:22963-73.

19. Gao C, Lin Z, Wu Z, Lin X, He Q. Stem-cell-membrane camouflaging on near-infrared photoactivated upconversion nanoarchitectures for in vivo remote-controlled photodynamic therapy. ACS Appl Mater Interfaces. 2016:8:34252.

20. Kumar S, Zakrewsky M, Chen M, Menegatti S, Muraski JA, Mitragotri S. Peptides as skin penetration enhancers: mechanisms of action. J Control Release. 2015;199:168-78.

21. Ashtikar M, Nagarsekar K, Fahr A. Transdermal delivery from liposomal formulations - evolution of the technology over the last three decades. J Control Release. 2016;242:126-40.

22. Amjadi M, Sheykhansari S, Nelson BJ, Sitti M. Recent advances in wearable transdermal delivery systems. Adv Mater. 2018;30:1704530.

23. Bäsler K, Bergmann S, Heisig M, Naegel A, Zorn-Kruppa M, Brandner JM. The role of tight junctions in skin barrier function and dermal absorption. J Control Release. 2016;242:105-18.

24. Nagai N, Ogata F, Ishii M, Fukuoka Y, Otake H, Nakazawa Y, et al. Involvement of endocytosis in the transdermal penetration mechanism of ketoprofen nanoparticles. Int J Mol Sci. 2018;19:E2138.

25. Campbell RL, Bruce RD. Direct comparison of rabbit and human primary skin irritation responses to isopropylmyristate. Toxicol Appl Pharmacol. 1981;59:555-63.
26. DiTommaso T, Cottle DL, Pearson HB, Schluter H, Kaur P, Humbert PO, et al. Keratin 76 is required for tight junction function and maintenance of the skin barrier. PLoS Genet. 2014;10:e1004706.

27. Kubo A, Nagao K, Yokouchi M, Sasaki H, Amagai M. External antigen uptake by Langerhans cells with reorganization of epidermal tight junction barriers. J Exp Med. 2009;206:2937-46

28. Doherty GJ, McMahon HT. Mechanisms of endocytosis. Annu Rev Biochem. 2009;78:857-902.

29. Tashtoush BM, Jacobson EL, Jacobson MK. UVA is the major contributor to the photodegradation of tretinoin and isotretinoin: implications for development of improved pharmaceutical formulations. Int J Pharm. 2008;352:123-8.

30. El Maghraby GM, Barry BW, Williams AC. Liposomes and skin: from drug delivery to model membranes. Eur J Pharm Sci. 2008;34:203-22.

31. Franzé S, Donadoni G, Podestà A, Procacci P, Orioli M, Carini M, et al. Tuning the extent and depth of penetration of flexible liposomes in human skin. Mol Pharm. 2017;14:1998-2009.

32. Yang M, Gu Y, Yang D, Tang X, Liu J. Development of triptolide-nanoemulsion gels for percutaneous administration: physicochemical, transport, pharmacokinetic and pharmacodynamic characteristics. J Nanobiotechnol. 2017;15:88

33. Urwyler-Rösselet C, Tanghe G, Leurs K, Gilbert B, De Rycke R, De Bruyne $M$, et al. Keratinocyte-specific ablation of RIPK4 allows epidermal cornification but impairs skin barrier formation. J Invest Dermatol. 2018:138:1268-78.

\section{Publisher's Note}

Springer Nature remains neutral with regard to jurisdictional claims in published maps and institutional affiliations.
Ready to submit your research? Choose BMC and benefit from:

- fast, convenient online submission

- thorough peer review by experienced researchers in your field

- rapid publication on acceptance

- support for research data, including large and complex data types

- gold Open Access which fosters wider collaboration and increased citations

- maximum visibility for your research: over $100 \mathrm{M}$ website views per year

At BMC, research is always in progress.

Learn more biomedcentral.com/submissions 